\title{
Analysis on the Enlightenment of marketing conception to non-profit organizations
}

\author{
WeiDong Xi, WenJuan Shao \\ (Dalian Institute of Science and Technology, Dongbei University of Finance and \\ Economics )
}

Keywords: marketing conception; non-profit organizations; enlightenment

Abstract: With the development of socialist market economy, the market marketing conception came into being, providing direction guidance for for-profit enterprises, and promoting the further development of social economy. In this new environment of market economy development, if the non-profit organizations want to have made great progress, according to the actual situation of the development of the market economy, Integrate the modern marketing concept into the development of non-profit organizations, thus to guide the further development of the non-profit organization. This paper aims to analyze and explore the enlightenment of the marketing conception to the non-profit organizations, and promote the rapid development of non-profit organizations.

\section{Introduction}

Because of the rapid development of social economy, the social environment of non-profit organizations has changed, if non-profit organizations in china want to get a better development space they need to introduce the marketing concept into the development of non-profit organizations, so as to ensure the long-term development of non-profit organizations. Using the marketing conception to guide the actual development of non-profit organizations, promote the further development of non-profit organizations.

\section{The marketing conception needs in non-profit organizations}

In the theory of " marketing management" , " marketing " is defined as: " marketing is a process of acquiring the necessary items through the exchange of the same value products to individuals or groups, and to obtain the corresponding products, it is belonging to a social management process. " In the marketing conception, marketing is a means to meet the most basic needs of people, these basic needs are mainly food, clothing, etc. which can provide the necessary life for people's real life ${ }^{[1]}$ and meet the needs of people's development, The value of products mainly lies the products can produce the greatest social benefits in the use of products, Once people exchange their products in exchange for products to meet their needs, this produces marketing. Compared to non-profit organizations, profitability is not the main purpose, but through effective market management to maximize the social benefits, which is the biggest difference between non-profit organizations and for-profit organizations. Although the marketing conception is for the further development of for-profit enterprises, and derived a marketing management conception, non-profit organizations can choose the appropriate management conception according to the relevant content, non-profit organizations can according to their actual development to introduce the marketing conception to guide the further development of non-profit organizations.

\section{The application of marketing conception in non-profit organization}

\subsection{The concept of social marketing}

The non-profit organization in the process of social development, belongs to a service industry, social marketing is a kind of marketing conception with two different properties of economic man and social man, can use the form of commodity trading to achieve the social commonweal purpose of non-profit organizations, or to achieve social services through commodity trading. In this process, enterprises participate in the marketing activities with social commonweal identity, and take the 
customer's market demand as the orientation of enterprise marketing, provide customers with higher satisfaction social marketing service ${ }^{[2]}$, so as to achieve the purpose of enterprise production marketing. According to the social marketing conception, many experts in China also explore and discuss the social marketing concept, according to the actual situation of non-profit organizations, to guide the practice of non-profit organizations, such as more common social volunteers, charitable donors and so on can provide corresponding financial support, broaden the sources of funds of enterprises.

\subsection{Image marketing conception}

The image marketing conception mainly refers to the social influence that enterprises produce in the social economic activities, in the social masses. In the actual enterprise development process, according to the actual situation of the market public evaluation to carry out marketing activities, In order to achieve the established development goal, enterprises need to use the corresponding public relations stakeholders to communicate information to ensure the social status of enterprises and deepen the people's social image of enterprises[3]. Therefore, the image marketing conception is mainly through the social influence and brand image of products to carry out the corresponding marketing, further expand the market influence of commodities, so as to improve the market competitiveness of enterprises. This is a very important management conception for non-profit organizations which can help non-profit organizations to shape good social image and optimize the social benefits of non-profit organizations.

\subsection{Network marketing conception}

With the development of modern science and technology, internet technology has been widely used in the development of enterprises. With the help of the Internet platform, we can carry on the corresponding propaganda to the commodity, widen the channel of commodity trade and make the commodity marketing plan of different strategies according to the actual needs of the customers, to meet the diverse service needs of customers[4]. Network marketing conception has the characteristics of interactive, face to face and so on, enterprises can communicate with customers and understand the actual needs of customers, then change their marketing strategy, and promote the rapid development of enterprises. This network marketing conception can further expand the propaganda channels of non-profit organizations and provide a broader development space for the rapid development of non-profit organizations.

\subsection{Channel marketing conception}

In the development of non-profit organizations, the marketing channels of enterprises mainly cover the social resources collection channels and social resources use channels. For non-profit organizations, profit is not the ultimate goal of enterprise development, and it can not rely on profit to guide the further development of enterprises, in order to fully understand the various sources of funding[5], which requires extensive collection of corporate social resources, such as individual donations, corporate fund-raising, Is a source of funding for non-profit organizations, need to collect and sort out information from this source. The social resources use channels, mainly non-profit organizations in the development process will according to the social situation, provides a financial services, such as the Wenchuan earthquake, social fund-raising, to provide the corresponding financial support for Wenchuan, which is a form of funds.

\section{The enlightenment of marketing conception to the development of non-profit organizations}

\subsection{Social marketing conception can provide more employment opportunities.}

Nonprofit organizations in maintaining operational development need to spend a lot of constructive funds, each year needs to select the appropriate site, various mechanical equipment, office supplies, etc., this is a material consumption, can effectively pull domestic demand and expand the employment market. With the help of social marketing conception to achieve the social commonweal purpose, non-profit organizations can provide the corresponding jobs, and then use marketing conception to manage, which can maintain the balance of supply and demand of social and economic development to some extent. 


\subsection{Expanding the influence of non-profit organizations with the image marketing conception}

Non-profit organizations in the development process, the organization wants to achieve rapid development and achieve the established goal of organizational development, it needs to use the image marketing conception to expand the social influence of non-profit organizations, find out the corresponding public relations interests subject of non-profit organizations, transfer information through modern media media can effectively communicate with the interests of both sides, give full play to the social role of non-profit organizations and expand the social influence of non-profit organizations.

\subsection{Expanding the development space of non-profit organizations with the help of network marketing conception}

With the help of internet platform, it can quickly transfer the relevant information of non-profit organizations, increase the channel of information dissemination, and also enable the products produced by non-profit organizations to network marketing, which provides a broader space for the further development of non-profit organizations. At the same time, with the help of network marketing conception, they can further expand the information transmission channels of non-profit organizations, timely grasp and understand the information of relevant personnel, combine the actual situation and make the corresponding development strategy adjustment to ensure the rapid development of non-profit organizations.

\subsection{Meeting the needs of social diversification with the Channel marketing conception}

Due to the rapid development of social economy, people's material needs and spiritual needs also show diversification trend. And the service content of non-profit organizations is also rich diversity, such as the employment training, welfare assistance poor children, supporting rural education in remote areas and so on, which is the service content of non-profit organizations, this can not only provide diversified demand services, but also meet people's diversified needs, and promote further development of non-profit organizations.

\section{Summary:}

In conclusion, the marketing conception is used in the development of non-profit organizations, using modern marketing management conception to guide the development of non-profit organizations in socialist market economy, provide broader development space for non-profit organizations and help non-profit organizations to better integrate into market development, promote the further development of non-profit organizations.

\section{Acknowledgement}

Supported by China Postdoctoral Science Foundation fifty-eighth Grant No.: 2015M581343 Liaoning Provincial Social Science Fund "Liaoning province new agricultural insurance management service system construction" number "L15CG L005"

\section{Reference}

[1] Shen Pengyi, Zhang Ya. Analysis of influencing factors of service orientation behavior of NPO [J]. East China economic management, 2015 (07)

[2] Jiao Xiaobo, The application of market orientation in the marketing of NPO [J]. Rural economy and technology, 2016 (09)

[3] Chen Xiaochun, He Juhua, bu Xiaoyan. Analysis on the credibility construction of China's non-profit organizations [J]. Journal of Beihua University (Social Science Edition), 2014 (03).

[4] Li Yan, Zhao Changping, Shi Jianren. Study on the cultural marketing model of NPO [J]. Shopping mall modernization, 2016 (33)

[5] Li Yan, Shi Jianren, Zhao Changping. The enlightenment of niche theory of marketing for NPO [J]. Technical economics and management research, 2016 (04) 